\title{
Use of complementary and alternative medicine in children with asthma
}

\author{
Vanessa Torres-Llenza MD¹, Sanjit Bhogal MSc ${ }^{2}$, Michael Davis MBChB ${ }^{3}$, Francine M Ducharme MD FRCPC FAAP2
}

\author{
V Torres-Llenza, S Bhogal, M Davis, FM Ducharme. Use of \\ complementary and alternative medicine in children with asthma. \\ Can Respir J 2010;17(4):183-187.
}

BACKGROUND: Because of the potential risk of interaction with, and underuse of, conventional medications, it is important to document the prevalence of the use of complementary and alternative medicines (CAMs) in asthmatic children.

OBJECTIVE: To ascertain the prevalence and type of CAMs, and to identify factors associated with their use.

METHODS: A cross-sectional survey of children who presented to the Asthma Centre of The Montreal Children's Hospital (Montreal, Quebec) between 1999 and 2007 was conducted. At the initial consultation, parents completed a questionnaire inquiring, in part, about CAM use. Computerized health records provided information regarding patient characteristics and their condition.

RESULTS: The median age of the 2027 children surveyed was 6.1 years (interquartile range 3.3 to 10.5 years); $58 \%$ were male and $59 \%$ of children had persistent asthma. The prevalence of CAM use was 13\% (95\% CI 12\% to $15 \%)$. Supplemental vitamins (24\%), homeopathy (18\%) and acupuncture $(11 \%)$ were the most commonly reported CAMs. Multivariable logistic regression analysis confirmed the association of CAM use with age younger than six years (OR 1.86; 95\% CI 1.20 to 2.96), Asian ethnicity (OR 1.89; 95\% CI 1.01 to 3.52 ), episodic asthma (OR $1.88 ; 95 \%$ CI 1.08 to 3.28 ) and poor asthma control (OR 1.98; 95\% CI 1.80 to 3.31 ).

CONCLUSION: The prevalence of reported CAM use among Quebec children with asthma remained modest (13\%), with vitamins, homeopathy and acupuncture being the most popular modalities. CAM use was associated with preschool age, Asian ethnicity, episodic asthma and poor asthma control.

Key Words: Alternative medicine; Asthma; Complementary medicine; Determinants; Pediatric; Prevalence

$\mathrm{T}$ he use of nonconventional medicine for the diagnosis, prevention and/or treatment of pediatric conditions is a reality (1), and is particularly true for the management of childhood asthma (2,3). The American Medical Association compiled an extensive list of nonconventional therapies (4) that are referred to as complementary or alternative medicine (CAM) when used in addition to, or as a replacement for, conventional medicine. While there is little scientific evidence to support the efficacy of CAM in children with asthma (5-9), surveys (10) have reported that $59 \%$ of parents believe that CAMs are effective, and $44 \%$ admitted to using CAM before bronchodilators in the initial home management of asthma flares. More disturbing are reports (10) that one-half of parents who use CAM for the management of their child's asthma do so without informing their doctor. Parents may not be aware of the risks associated with the use of CAM, including the delay in taking, and potential interaction with, conventional asthma

\section{Utilisation des approches complémentaires et parallèles en santé chez les enfants asthmatiques}

HISTORIQUE : En raison du risque potentiel d'interaction avec les médicaments d'usage courant et de leur sous-utilisation, il est important de documenter la prévalence du recours aux approches complémentaires et parallèles en santé (ACPS) chez les enfants asthmatiques.

OBJECTIF : Vérifier la prévalence de l'utilisation des ACPS et les types utilisés et reconnaître les facteurs associés à leur utilisation.

MÉTHODE : Une enquête transversale auprès d'enfants traités au Centre de traitement de l'asthme de l'Hôpital pour enfants de Montréal (Montréal, Québec) entre 1999 et 2007 a été réalisée. Au moment de la consultation initiale, les parents ont répondu à un questionnaire portant entre autre sur l'utilisation des ACPS. Les dossiers de santé informatisés ont fourni des renseignements sur les caractéristiques et l'état de santé des patients.

RÉSULTATS : L'âge médian des 2027 enfants ainsi sondés était de 6,1 ans (éventail interquartile 3,3 à 10,5 ans), $58 \%$ étaient de sexe masculin et $59 \%$ souffraient d'asthme persistant. La prévalence de l'utilisation des ACPS était de $13 \%$ (IC à $95 \%, 12 \%$ à $15 \%$ ). Les ACPS les plus utilisées étaient les suppléments vitaminiques (24\%), l'homéopathie $(18 \%)$ et l'acupuncture $(11 \%)$. Une analyse de régression logistique multivariée a confirmé le lien entre l'utilisation des ACPS et un âge inférieur à six ans (RC 1,86, IC à $95 \%, 1,20$ à 2,96), l'origine asiatique (RC 1,89, IC à $95 \%$, 1,01 à 3,52), l'asthme épisodique (RC 1,88, IC à $95 \%, 1,08$ à 3,28) et un piètre contrôle de l'asthme (RC 1,98, IC à $95 \%, 1,80$ à 3,31).

CONCLUSIONS : La prévalence de l'utilisation des ACPS signalée chez les enfants du Québec souffrant d'asthme est demeurée modeste (13\%), les vitamines, l'homéopathie et l'acupuncture ayant été les modalités les plus populaires. Le recours aux ACPS a été associé à un âge préscolaire, à l'origine asiatique, à l'asthme épisodique et à un piètre contrôle de l'asthme.

therapy. Health care professionals should be aware of the prevalence of, and the factors associated with, CAM use in their practice area to guide their inquiry regarding nonconventional management among their patients.

Regardless of the presence and type of medical conditions, the reported use of CAM among children varies widely across settings and countries, from 11\% in Canada (1) and 25\% in England (11), to $53 \%$ in Denmark (12). Respiratory diseases appear to be the most common conditions for which CAM is used $(1,11,12)$. CAM use by asthmatic children and adolescents is reported to be as high as $52 \%$ in some areas of Australia (3), and $65 \%$ to $89 \%$ in the United States $(2,10,13)$. Vitamins, minerals and herbal preparations tend to be the most frequently used CAMs $(2,3,14,15)$, thus raising the theoretical risk of interactions with conventional asthma medications $(16,17)$. Attempts to identify the factors associated with CAM use have been hampered, in part, by the small sample size of most pediatric studies $(3,18)$.

${ }^{1}$ Universidad Central del Caribe School of Medicine, Bayamón, Puerto Rico, USA; ${ }^{2}$ Applied Clinical Research Unit, Research Centre, Centre hospitalier universitaire Sainte-Justine and Department of Paediatrics, University of Montreal; ${ }^{3}$ Department of Paediatrics, The Montreal Children's Hospital, McGill University Health Centre, McGill University, Montreal, Quebec

Correspondence: Dr Francine M Ducharme, Department of Paediatrics, Centre hospitalier universitaire Sainte-Justine, 3175 Cote Sainte-Catherine, Montréal, Québec H3T 1C5. Telephone 514-345-4931 ext 7171 or 4398, fax 514-345-4822, e-mail francine.m.ducharme@umontreal.ca 
The purpose of the present study was to ascertain the prevalence and type of CAM use among asthmatic children presenting to a tertiary care pediatric asthma centre in Quebec. Moreover, we attempted to identity factors associated with CAM use to identify subgroups of patients that could be targeted to study the reasons for, and potential impact of, CAM use in childhood asthma.

\section{METHODS}

\section{Design}

A cross-sectional study using data from standardized questionnaires that were completed by parents of all children presenting to the Asthma Centre of The Montreal Children's Hospital (Montreal, Quebec) for an initial visit between 1999 to 2007, was conducted. The Director of Professional Services of the Montreal Children's Hospital, McGill University Health Centre (Montreal, Quebec), approved and waived the need for an ethics review of the present quality improvement initiative for the care of children with asthma.

\section{Study population}

Eligibility criteria included children one to 17 years of age who had an initial consultation at the Asthma Centre following a physician-confirmed diagnosis of asthma. Patients with other chronic respiratory conditions such as bronchopulmonary dysplasia and cystic fibrosis were excluded. Because inquiry regarding CAM use was systematically made only at the initial encounter, data from repeat visits were specifically excluded.

\section{Procedures and outcomes}

At the intitial assessment, as per standard procedures, all parents completed a questionnaire regarding family history of atopy, environmental triggers - including tobacco smoke exposure - and the use of CAMs. Children were classified as using CAM if parents answered 'yes' to the following question: "Is the child currently receiving any form of alternative medicine to improve his or her asthma?" Users were then asked to identify which of the following listed CAMs were used: acupuncture, chiropractic, herbs, homeopathy, naturopathy, oligotherapy, osteopathy, vitamin supplements and others. No specific descriptions of the various CAM types were provided.

The computerized health records of the Asthma Centre included information regarding patient demographics (age, sex and ethnicity); neighbourhood income, which was estimated from postal codes; health care resource use in the previous year; asthma phenotype (persistent, episodic or seasonal); environmental triggers; asthma severity; asthma control and associated comorbidities; and prescribed asthma medications. Physicians rated asthma control as good, fair or poor, based on a global assessment derived from history, examination and, if available, lung function tests. Asthma severity was assessed according to the intensity of treatment required to maintain control: patients who did not take or used low doses of inhaled corticosteroids (less than $400 \mu \mathrm{g} /$ day of chlorofluorocarbon-propelled beclomethasone dipropionate [CFC-BDP] or equivalent) were assumed to have mild asthma; patients who were prescribed low doses of inhaled corticosteroids with adjunct therapy (eg, longacting beta-2 agonists or antileukotrienes) or moderate doses (more than $400 \mu \mathrm{g} /$ day but less than $800 \mu \mathrm{g} /$ day) of CFC-BDP or equivalent were considered to have moderate asthma; patients who were prescribed moderate doses of inhaled corticosteroids with adjunct therapy or high doses of CFC-BDP (more than $800 \mu \mathrm{g} /$ day $)$ or equivalent $(6,19,20)$ were considered to have severe asthma.

\section{Statistical analysis}

Prevalence was reported as proportion with 95\% CI. A sensitivity analysis was conducted assuming that eligible patients in whom the use of CAM was not documented were all users and then repeated, assuming all were nonusers. Group differences in the factors associated with CAM use were determined using the $\chi^{2}$ test for categorical variables and the Wilcoxon-MannWhitney $\mathrm{U}$ test for continuous variables and reported as OR with 95\% CI using logistic regression analysis. A multiple logistic regression analysis was conducted using backward selection to examine the relative contribution of various variables. Candidate variables were those with a significant bivariate association with CAM use, and those previously reported as predictors or potential confounding variables of CAM use (eg, asthma severity, control, ethnicity, smoking exposure and socioeconomic status of the parents) $(3,15,21)$. The main model included these variables, regardless of the percentage of missing values. A sensitivity analysis that included only candidate variables documented in more than $65 \%$ of the children was repeated. Because age was notably skewed toward younger children, it was categorized into two groups using the overall group median as the cut-off (younger than six years of age, and six years of age or older). $\mathrm{P}<0.05$ was considered to be statistically significant. The data were analyzed using SAS version 9.1 (SAS Institute Inc, USA).

\section{RESULTS}

Of the 3195 children who had an initial consultation at the Asthma Centre, 558 (17\%) did not meet the eligibility criteria, resulting in 2637 eligible children (Figure 1). The status of CAM use was unknown for 610 (23\%) patients. Thus, 2027 children, which included 273 CAM and 1754 non-CAM users, constituted the sample cohort of the present study.

The prevalence of CAM use was $13 \%$ (95\% CI $12 \%$ to $15 \%$ ). The prevalence of CAM use rose to $21 \%$ (95\% CI $20 \%$ to $23 \%$ ) when all patients with unknown CAM status were assumed to be users. When all patients with an unknown CAM status were assumed to be non-CAM users, the prevalence was $12 \%$ (95\% CI $11 \%$ to $14 \%$ ). The most popular types of CAMs were supplemental vitamins, homeopathy and acupuncture (Table 1). The reported use of CAM over time remained relatively stable, ranging from 15\% in 1999, to $14 \%$ in 2007.

Bivariate analyses revealed significant group differences in age, ethnicity, asthma phenotype and asthma control between CAM and non-CAM users (Table E1). Multivariate logistic regression analysis demonstrated a positive association between CAM use and young age, Asian ethnicity, episodic asthma and poor asthma control (Table 2). A sensitivity analysis using only candidate variables recorded in more than $65 \%$ of patients (thus excluding asthma control) confirmed a similar strength of association between CAM use and age (OR 1.94; 95\% CI 1.39 to 2.71), Asian ethnicity (OR 1.77; 95\% CI 1.08 to 2.89) and episodic asthma (OR 1.5; 95\% CI 1.08 to 2.07). CAM users were more likely to be younger than six years of age compared with nonusers (59\% versus $47 \%, \mathrm{P}<0.001$ ) (Figure $\mathrm{E} 1$ ). 


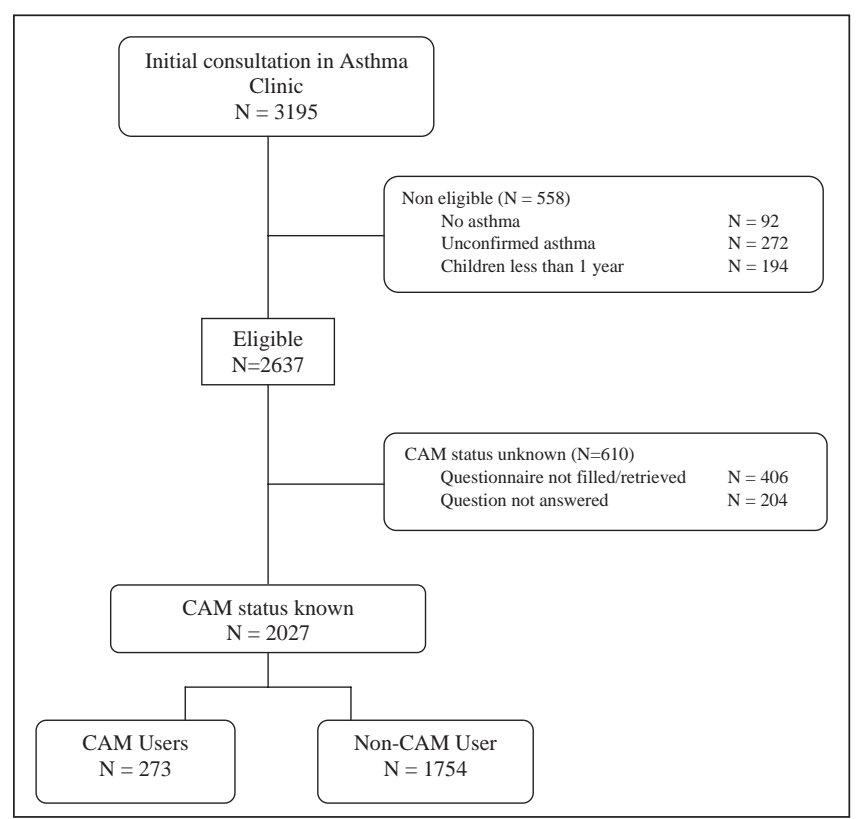

Figure 1) Patient selection. CAM Complementary and alternative medicine

\section{DISCUSSION}

In the present large survey of more than 2000 Canadian children with asthma, the parent-reported prevalence of CAM use was $13 \%$. Of all modalities, vitamins, homeopathy and acupuncture accounted for more than $50 \%$ of CAM use. Patient characteristics that were positively associated with CAM use included preschool age, Asian ethnicity, episodic asthma and poor asthma control.

The prevalence of CAM use among children presenting for an initial consultation to our asthma centre was consistent with the $11 \%$ prevalence rate reported in 1994 in Canadian children with various conditions, including asthma (1). It is also inline with the $6 \%$ usage rate reported in a large population survey (22) of children and adults with asthma in the United Kingdom. The prevalence reported in our study, however, is three- to fivefold lower than that reported in the pediatric American surveys $(2,10,13)$. The reasons for the wide variability in CAM use in children with asthma between these two adjacent North American countries are unclear. We hypothesized that the lower observed prevalence may be due to differences in survey methods, patients' eligibility criteria, the spectrum of CAMs considered, access to conventional medical care and/or subsidized drug plans. Indeed, in contrast to several studies, our survey was not anonymous because we instructed parents to complete and return the questionnaire to their physician, raising the possibility of under-reporting due to a social desirability bias. Second, we sampled children presenting to a tertiary care centre who may have been more receptive to, and satisfied with, conventional therapy than an unselected population-based sample. While satisfaction with conventional therapy has been associated with low CAM use, the association was, in fact, demonstrated in a large population-based survey (22), thus raising doubt as to the importance of a selection bias in our centre. Third, several studies used a broader definition of CAM than ours, including mind-body medicine (eg, prayer, yoga, etc) and massotherapy (eg, rubs and massages), which
TABLE 1

Type of complementary and alternative medicine used

\begin{tabular}{lc}
\hline & Users $^{*} \mathbf{n}(\%)$ \\
\hline Vitamins & $46(24)$ \\
Homeopathy & \\
Acupuncture & $34(18)$ \\
Chiropractic & $20(11)$ \\
Oligotherapy & \\
Other & $17(9)$ \\
Herbs & $16(8)$ \\
Naturopathy & $15(8)$ \\
Osteopathy & $14(7)$ \\
\hline
\end{tabular}

*The type of complementary and alternative medicine (CAM) was provided by 190 (70\%) of the 273 parents who reported CAM use in their children; ${ }^{+}$Homeopathy assumes that a medicinal substance that can evoke certain symptoms in healthy individuals may be effective in treating illnesses if given in very small doses; ${ }^{\ddagger}$ Oligotherapy refers to the use of remedies using trace elements normally found in the human body that are believed to act as catalysts in maintaining physiological functions; ${ }^{\S}$ Naturopathy depends on selfhealing using only natural forces based on energy fields and in which no surgical or medicinal agents are used; "Osteopathy emphasizes a holistic approach using manual and physical interventions based on the concept that the musculoskeletal system has an important role in disease and healing

TABLE 2

Variables associated with complementary and alternative medicine use

\begin{tabular}{ll}
\hline Variable & Adjusted OR (95\% Cl) \\
\hline Age, years & \\
$\geq 6$ & 1.0 \\
$<6$ & $1.86(1.20-2.96)$ \\
Ethnicity & 1.0 \\
Caucasian & $0.80(0.34-1.78)$ \\
Black & $1.89(1.01-3.52)$ \\
Asian & $0.83(0.38-1.91)$ \\
Other & \\
Asthma type & 1.0 \\
Persistent & $1.88(1.08-3.28)$ \\
Episodic & $0.66(0.14-3.11)$ \\
Seasonal & \\
Asthma control & 1.0 \\
Good & $1.22(0.57-2.59)$ \\
Fair & $1.98(1.80-3.31)$ \\
Poor &
\end{tabular}

OR of 1.0 denotes the reference category

were reported by as many as $45 \%$ of parents of asthmatic children in previous surveys $(10,11,15)$. We elected not to survey parents on the use of these latter therapies because of their negligible risk of adverse effects or interaction with conventional therapies. Interestingly, although vitamins, homeopathy and acupuncture were identified as the most frequently used CAMs, their prevalence in our population remained lower than that reported in other studies $(3,11)$. Finally, perhaps the universal access to traditional health care in Canada, and to free medications for children in Quebec, made the use of CAM less attractive than in countries in which health care access and drugs may be more restricted or costly. These hypotheses clearly need to be investigated further. 
Age (14), ethnicity (15), asthma phenotype (3), asthma control (21) and socioeconomic status (15) have previously been associated with CAM use. With the exception of the latter factor, our findings supported these associations. The multiple logistic regression analysis permitted quantification of the strength of the associations - that is, an $80 \%$ or higher rate of CAM use in patients who were of preschool age, of Asian ethnicity, who had episodic asthma or poor asthma control. Moreover, the identification of the same factors (eg, age, ethnicity and asthma phenotype) with similar strengths of association, after the exclusion of variables with a large proportion of missing values, underlies the robustness of our findings.

The assessment of the effectiveness of CAM in pediatrics is restricted by the scarcity of studies. The few well-designed trials in this area have failed to provide any evidence for the effectiveness of acupuncture $(7,23)$, homeopathy $(8,24)$, chiropractic medicine (6) or herbal therapy (25). Moreover, CAM use is not as benign as it may be perceived. In a cross-sectional study of adults with asthma, the use of chamomile, garlic and chili was associated with a two- to threefold increased rate of hospital admission for asthma compared with nonusers, perhaps reflecting the delayed use of efficacious medications (26). Moreover, almost all CAM therapies have been associated with adverse effects - a hypersensitivity reaction being the most frequent (17). In view of the high prevalence of childhood asthma (27), the lack of documented efficacy of CAM $(5,6,28)$, and the possibility of adverse health events associated directly or indirectly (due to delayed use or decreased compliance with traditional asthma management) with CAM use, it appears worthwhile to further explore the reasons for CAM use in childhood asthma.

The wide age spectrum, the large sample size - which included more than 2000 patients - and the systematic inquiry of CAM use at the first consultation constitute the strengths of the present study. However, we acknowledge the following limitations. First, the cross-sectional design precluded any conclusion regarding the causal and temporal relationship with CAM use. For example, one cannot determine whether poor asthma control motivated - or resulted from - the use of CAM. Second, missing data are a common problem with the use of health records, which raises the possibility of recording bias and/or inaccurate estimation of association in less frequently documented variables. Ethnicity, median neighbourhood income, school absence, asthma control and type of CAM were recorded in $41 \%$ to $70 \%$ of patients, thus precluding reliable assessment of association of these variables with CAM use and type. All other data were available for $85 \%$ or more of patients.

\section{REFERENCES}

1. Spigelblatt L, Lainé-Ammara G, Pless I, Guyver A. The use of alternative medicine by children. Pediatrics 1994;94:811-4.

2. Sidora-Arcoleo K, Yoos HL, McMullen A, Kitzman H.

Complementary and alternative medicine use in children with asthma: Prevalence and sociodemographic profile of users. J Asthma 2007;44:169-75.

3. Shenfield G, Lim E, Allen H. Survey of the use of complementary medicines and therapies in children with asthma. J Paediatr Child Health 2002;38:252-7.

4. American Medical Association. Report 12 of the Council on Scientific Affairs (A-97), 1997. <http://www ama-assnorg/ama/pub/ category/13638 html> (Accessed on July 29, 2007).

5. Spigelblatt LS. Alternative medicine: Should it be used by children? Curr Probl Pediatr 1995;25:180-8.
However, in the secondary analysis that excluded variables with a large proportion of missing data, the identification of the same predictors of CAM use with similar strengths of association underlies the robustness of our findings. Third, the subjectivity associated with the physicians' prescribing patterns and their assessment of asthma phenotype, severity and control would tend to underestimate any true association, thus reinforcing the significance of our findings. Fourth, without the specific documentation of purchase or alternative practitioner encounters, there is a possibility of misclassification or underreporting of CAM use by parents. The pattern of use remains to be defined because we did not record the frequency, timing and intensity of use, nor did we inquire whether CAM was used as a complement or an alternative to traditional medication, prophylactically or curatively, or whether use was associated with delayed or decreased compliance to traditional medicine. Finally, the reasons and beliefs associated with the use of alternative medicine were not addressed.

\section{CONCLUSION}

The prevalence of reported CAM use in children with asthma consulting a tertiary care centre was modest, with vitamins, homeopathy and acupuncture being the most popular. CAM use was associated with preschool age, Asian ethnicity, episodic asthma and poor asthma control. These factors may serve as indicators to remind health care professionals to inquire about CAM use, initiate appropriate counselling and to identify groups at higher risk of CAM use for future research.

ACKNOWLEDGEMENTS: The authors acknowledge the assistance of the staff of the asthma research team that contributed to this study including Sandy Resendes and Cheryl Savdie for assistance with database management, Lyudmyla Khomenko for data management, Janine Dumont and Karlyne Guilbeault for secretarial assistance, and the medical staff of the Asthma Centre in the Montreal Children's Hospital (Montreal, Quebec). The authors are members of the Research Institute of the McGill University Health Centre or the Research Centre of the CHU Sainte-Justine (Montreal, Quebec), and were supported in part by the Fonds de la recherche en santé du Québec.

DISCLOSURE: Vanessa Torres-Llenza was supported by the American Paediatric Society/Society for Paediatric Research and the National Institute of Child Health and Human Development (2-T35-HD7446). This study was presented in part at the Paediatric Academic Societies and Asian Society for Paediatric Research in Honolulu, Hawaii, USA in May 2008.

6. Hondras MA, Linde K, Jones AP. Manual therapy for asthma. Cochrane Database Syst Rev 2005; (2):CD001002.

7. Linde K, Jobst K, Panton J. Acupuncture for chronic asthma. Cochrane Database Syst Rev 2000;(2):CD000008.

8. Linde K, Jobst KA. Homeopathy for chronic asthma. Cochrane Database Syst Rev 2000;(2):CD000353.

9. Linde K, Jonas W. Are the clinical effects of homeopathy placebo effects? Lancet 2005;366:2081-2.

10. Braganza S, Ozuah PO, Sharif I. The use of complementary therapies in inner-city asthmatic children. J Asthma 2003;40:823-7.

11. Simpson N, Roman K. Complementary medicine use in children: Extent and reasons. A population-based study. Brit J Gen Pract 2001;51:914-6. 
12. Madsen H, Andersen S, Nielsen RG, Dolmer BS, Host A, Damkier A. Use of complementary/alternative medicine among paediatric patients. Eur J Pediatr 2003;162:334-41.

13. Reznik M, Ozuah PO, Franco K, Cohen R, Motlow F. Use of complementary therapy by adolescents with asthma. Arch Pediatr Adolesc Med 2002;156:1042-4.

14. Sibinga EMS, Ottolini MC, Duggan AK, Wilson MH. Parent-pediatrician communication about complementary and alternative medicine use for children. Clin Pediatr 2004;43:367-73.

15. Ang JY, Ray-Mazumder S, Nachman SA, Rongkavilit C, Asmar BI, Ren CL. Use of complementary and alternative medicine by parents of children with HIV infection and asthma and well children. South Med J 2005;98:869-75.

16. Rivera JO, Hughes HW, Stuart AG. Herbals and asthma: Usage patterns among a border population. Ann Pharmaco 2004:38:220-5.

17. Bielory L. Complementary and alternative interventions in asthma, allergy, and immunology. Ann Allerg Asthma Immunol 2004;93(Suppl 1):S45-54.

18. Blanc PD, Trupin L, Earnest G, Katz PP, Yelin EH, Eisner MD. Alternative therapies among adults with a reported diagnosis of asthma or rhinosinusitis: Data from a population-based survey. Chest 2001;120:1461-7.

19. Becker A, Berube D, Chad Z, et al. Canadian Pediatric Asthma Consensus Guidelines, 2003 (updated to December 2004). CMAJ 2005;173(Suppl 6):S12-14.

20. Global Initiative for Asthma. Global strategy for asthma management and prevention, 2006. <www.ginasthma.org> (Accessed on December 11, 2007).
21. Orhan F, Sekerel BE, Kocabas CN, Sackesen C, Adalioglu G, Tuncer A. Complementary and alternative medicine in children with asthma. Ann Allerg Asthma Immunol 2003;90:611-5.

22. Partridge MR, Dockrell M, Smith NM. The use of complementary medicines by those with asthma. Respir Med 2003;97:436-8.

23. Stockert K, Schneider B, Porenta G, Rath R, Nissel H, Eichler I. Laser acupuncture and probiotics in school age children with asthma: A randomized, placebo-controlled pilot study of therapy guided by principles of traditional Chinese medicine. Pediatr Allergy Immunol 2007;18:160-6.

24. White A, Slade P, Hunt C, Hart A, Ernst E. Individualised homeopathy as an adjunct in the treatment of childhood asthma: A randomised placebo controlled trial.

Thorax 2003;58:317-21.

25. Murali PM, Rajasekaran S, Krishnarajasekar OR, et al. Plant-based formulation for bronchial asthma: A controlled clinical trial to compare its efficacy with oral salbutamol and theophylline. Respirology 2006;73:457-63.

26. Blanc PD, Kuschner WG, Katz PP, Smith S, Yelin EH. Use of herbal products, coffee or black tea, and over-the-counter medications as self-treatments among adults with asthma. J Allergy Clin Immunol 1997;100:789-911.

27. von Mutius E. The burden of childhood asthma. Arch Dis Child 2000;82(Suppl 2):II2-I5.

28. Markham AW, Wilkinson JM. Complementary and alternative medicines (CAM) in the management of asthma: An examination of the evidence. J Asthma 2004;41:131-9. 
TABLE E1

Patient characteristics associated with use of complementary and alternative medicine (CAM)

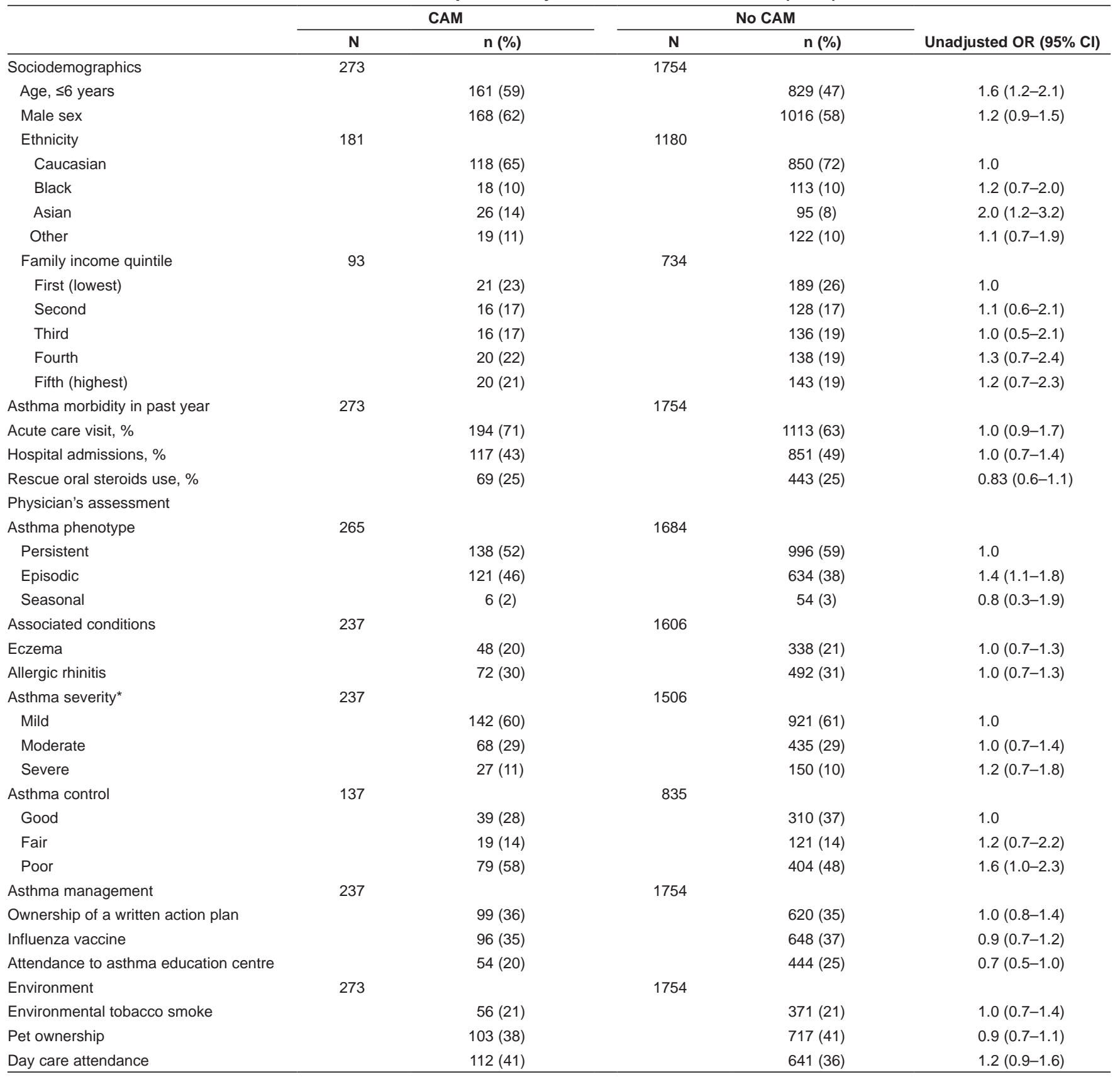

*Physicians assessed asthma severity according to the intensity of treatment required to maintain control: patients requiring no controller medication, nonsteroidal drugs or low doses of inhaled corticosteroids (ICS) (ie, $\leq 400 \mathrm{mcg} /$ day of chlorofluorocarbon-propelled beclomethasone or equivalent [CFC-BDP eq]) were deemed to have asthma of mild severity. Patients treated with moderate doses of ICS (ie, $400 \mathrm{mcg} /$ day to $799 \mathrm{mcg} /$ day of CFC-BDP $P_{\mathrm{ed}}$ ) or low doses of ICS with add-on therapy were considered to have moderate asthma. Asthma was identified as severe in children who required high doses of ICS ( $\geq 800 \mathrm{mcg} /$ day of CFC-BDP $\mathrm{eq})$ or moderate doses ICS with add-on therapy 


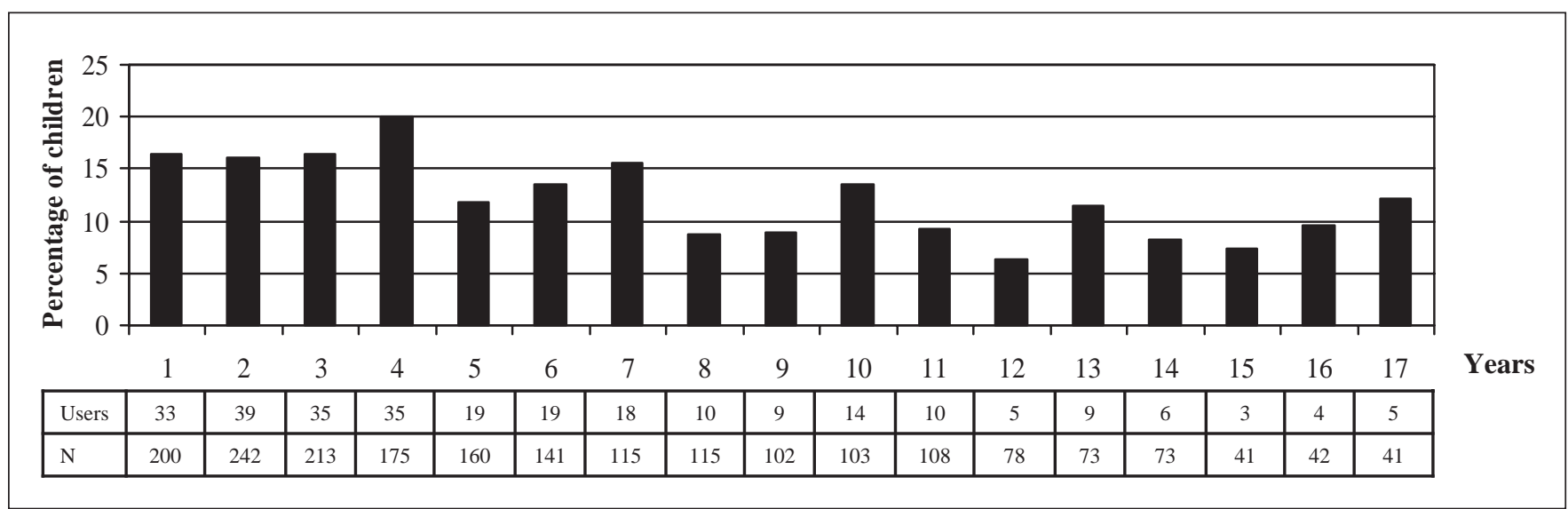

Figure E1. Complementary and alternative medicine use according to age (Years) 


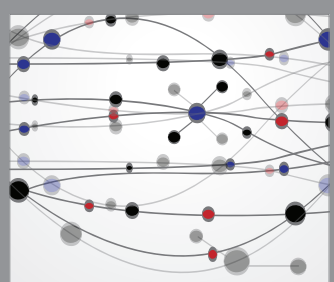

The Scientific World Journal
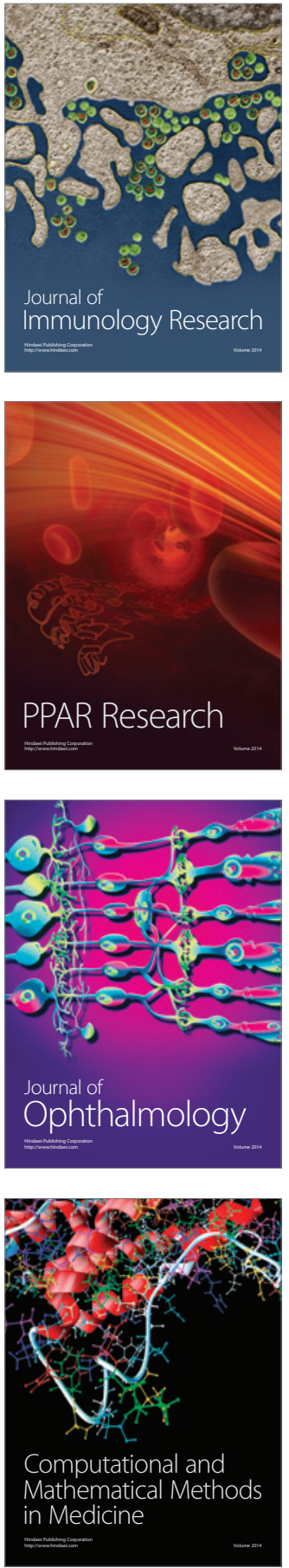

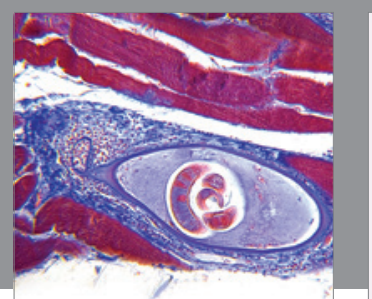

Gastroenterology Research and Practice

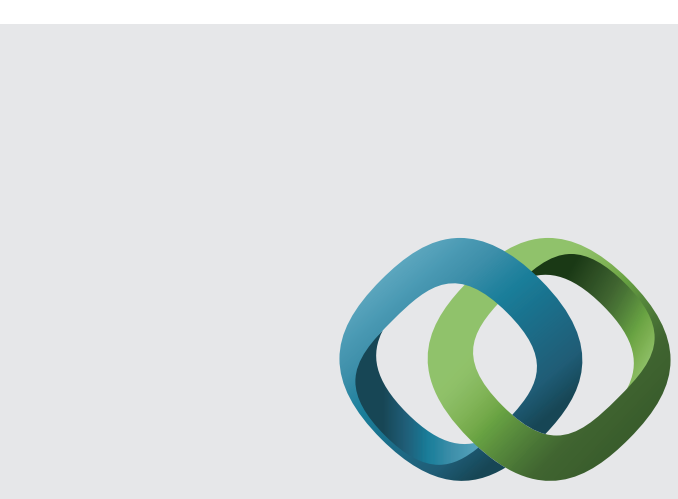

\section{Hindawi}

Submit your manuscripts at

http://www.hindawi.com
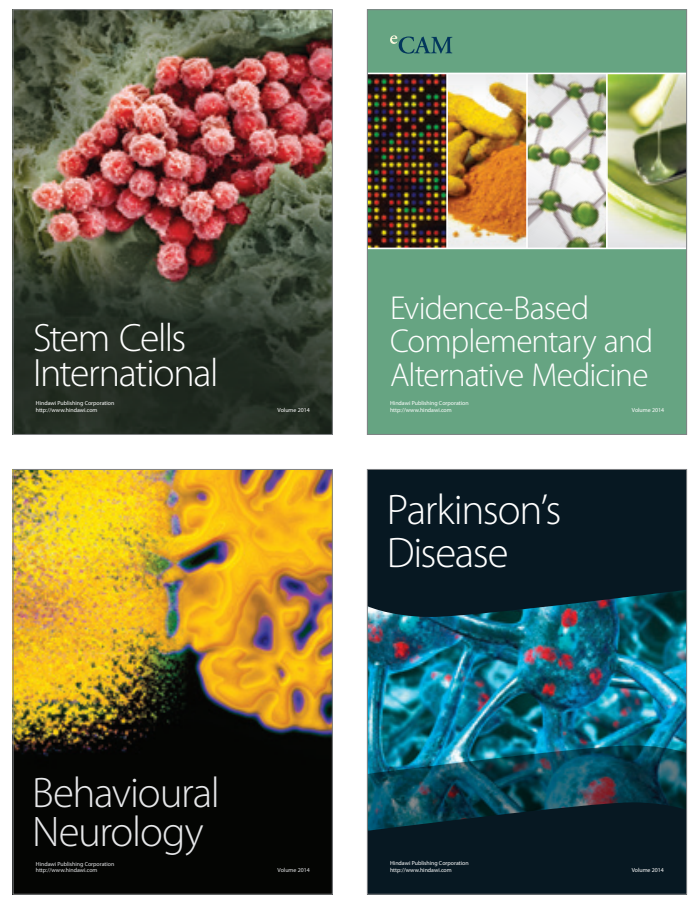
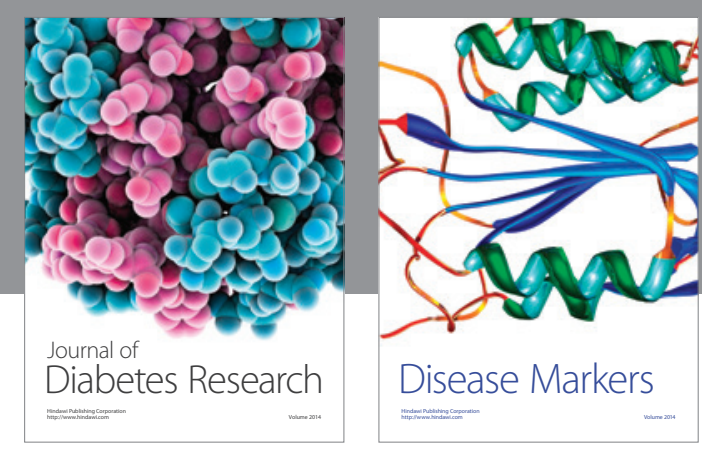

Disease Markers
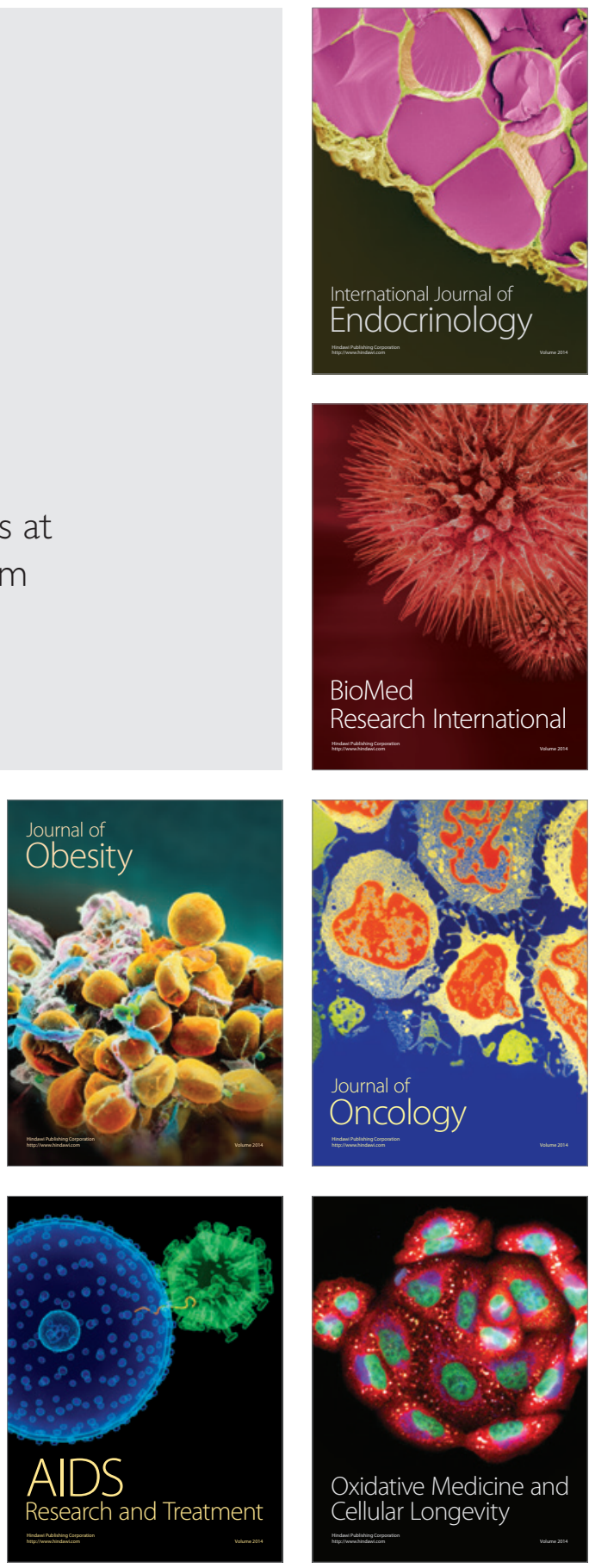